\title{
Erratum: Technology and education: Challenges and opportunities
}

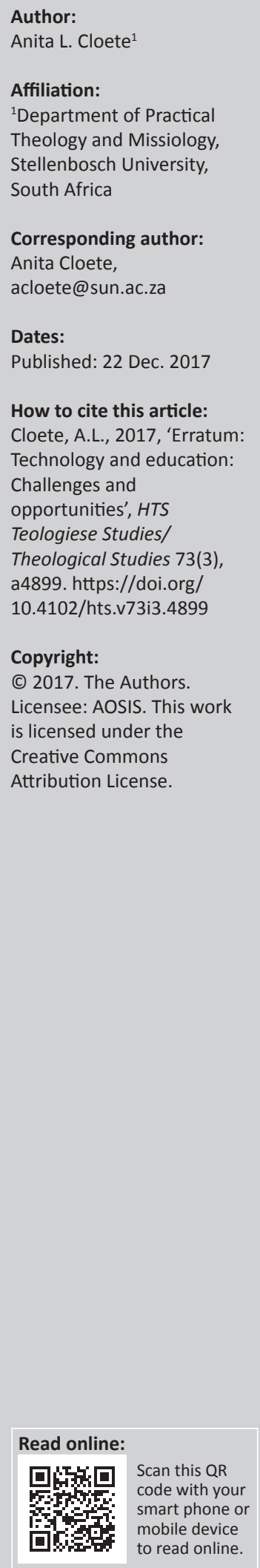

Scan this QR
code with your
smart phone or
mobile device
to read online.

The article was incorrectly categorised as part of Volume 73, Issue 4 of 2017. The article category is hereby corrected as a publication of Volume 73, Issue 3 of 2017. This correction does not alter the study's findings of significance or overall interpretation of the study results. The editor apologises for any inconvenience caused. 


\section{Technology and education: Challenges and opportunities}

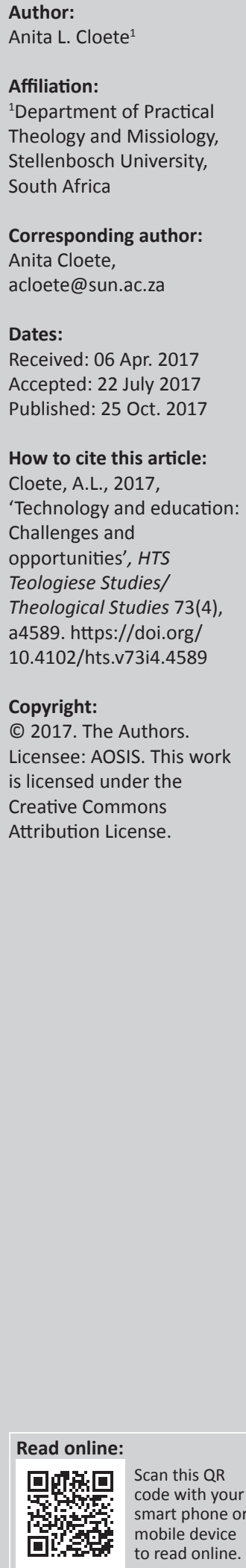

\begin{abstract}
This article seeks to contribute to the continuous reflection on the integration of technology into education. In order to accomplish this aim, the use of technology in the form of blended learning and online education will be utilised to illustrate how technology plays a central role in education today. It is argued that technology should not merely be viewed as a tool, but rather as a medium that shapes culture. Therefore, the integration of technology into education should be accompanied by continuous reflection on the identifiable characteristics of technology as medium that is not value-neutral or a disembedded force. To the contrary, technology is socially embedded and could be directly linked to other social developments and processes. The article therefore wishes to highlight the social embeddedness of technology by stressing how it is intertwined with other social developments like economy. In order to utilise technology more effectively and in a responsible manner in education, the nature thereof as medium should be reflected on. In light of the discussion on the technology as a socially embedded medium, the possible challenges and opportunities that it poses as medium to education, are identified and discussed. Specific reference is made on how theological education could benefit from educational technologies.
\end{abstract}

\section{Introduction}

The ongoing reflection on education and technology points to the diverse effect of technology on education. Therefore, this article will identify both possible challenges and opportunities that the integration of technology into education offers. A reflection on both the challenges and opportunities offered by technology in an educational environment prevents that we over- or underestimate the value of technology in education. The primary aim of the article is to illustrate the complex nature of technology as medium. It is pivotal to understand the complex nature of technology in order to integrate it effectively and in a responsible manner into quality education. Building on the argument that technology is not a tool, but rather a medium that is shaping culture today, a discussion on the social embeddedness of technology as one of its outstanding characteristics, is outlined in the first section. In the light of that discussion, the following challenges will be attended to: the commodification of knowledge and education and how technology is the main driving force in this process. The complex nature of technology is introduced to dissect the possible implications for education. The impact of utilising technology in education differs from context to context and therefore specific reference is made to the implications in the South African context, followed by the opportunities technology offers with specific reference to theological education.

\section{The nature of technology as a socially embedded medium}

Ascough (2002:17) is of the opinion that 'good education requires an awareness of the opportunities and limitations of the mode of education'. In other words, an understanding of the nature of the medium is required before designing it as educational environment. In line with this argument of having an understanding of the medium, Hess (2002:30) suggests that research on education and technology should not simply focus on the question of how to use a simple tool. It should instead entail several culture questions. Technology as medium is understood as a source of meaning making (Hess 2002:32). Although we tend to think about technology as devices (gadgets) like a phone, car or computer, representing material entities, Drees (2002:599) cautions that technology is more than that and identifies certain dimensions of technology. Infrastructure, like receivers and transmitters, is identified as a core element of technology as no technology could function without it. Technology is also a social system referring to organisations that provide certain services. Skills are another dimension that are as important as hardware. Technology as attitude refers to an active attitude to analyse problems in order to find practical ways to address it. 
Lastly, technology is even more than these dimensions mentioned already because technology is also a culture (Drees 2002:600). Understanding technology as culture is more encompassing than the other dimensions as it speaks to the complex process of technology as mirroring who we are (identity), our desires (that guide our actions) and our values (that include our hopes and dreams). Drees (2002:603) therefore makes a valuable distinction between technology as design, which focuses on what technological specialists do, and technology as culture, which entails the interactions between technology and wider culture.

The significant development of technology is deeply embedded and part of other social developments. Therefore, the relationship between technological and economic development is worth taking note of. In the words of Allenby and Sarewitz (2011):

technology is not just a matter of innovation; it is also a matter of adoption by a critical mass of users, and it co-evolves with cultural, economic, political and other domains, each of which continually affects, and is in turn affected by the other. (p. 35)

Technology is therefore more than just infrastructure or a tool that could be utilised as found fit. It requires a new social contract and moral vision prescribing to a society what is valuable and important (Saravanamuthu 2002:79). The fact that information and communication are mediated through technology makes it very desirable and alternatives almost unthinkable.

Allenby and Sarewitz (2011:3) plot advanced and sophisticated technological developments within the framework of trans-humanism. They understand the transhuman discourse as just another variety of the technological optimism and argues that 'The ambitions of the transhumanism is comprehensive, extending beyond health and longevity to radically enhanced intelligence, creativity, and emotional capabilities' (Allenby and Sarewitz 2011:8). They also warn that we are increasingly blind to the world we are creating in which technology has a central role. They formulate the challenge as follows: '... people don't understand technology or the complexity that technology engenders'.

In an attempt to give an indication of the complexity of technology and its social embeddedness, Allenby and Sarewitz (2011:37-38) make a distinction between at least three levels. The first level refers to the immediate effectiveness and functionality of technology. It thus refers to the use of technology to accomplish a particular task, which is often done with high reliability - for example, an aircraft that could transport you from over extensive distances.

Level 2 entails the system complexity that often includes irrationality and dysfunction - for example, the pricing system and inefficiency of boarding and security process and delays. Despite the high prices of air tickets, airlines often become insolvent. Level 2 includes therefore many unintended consequences that are not predictable.
Level 3, however, includes a phenomena called 'technology lock in', which occurs when economy and culture coalesce with technology systems around a particular way of doing something. It is not claimed that these levels are necessarily clear and obvious, but it is an attempt to illustrate the different levels on which technology operates and the interdependence on other forms of technology and social economic policies, etc. It is therefore clear that technologies do not operate in isolation, but are intertwined with other social and cultural systems.

In the light of the importance to understand technology as medium specifically in the context of education, the following discussion will highlight certain characteristics and beliefs with regard to technology. Using technology is associated with the idea of keeping up with the times and pretends to be in step with a rapidly changing society and global environment. Among the multiple reasons and motives why universities engage with e-learning or online learning, widening access, increasing flexibility and cost-effectiveness are the most widely recognised rationale (Söderström et al. 2012:2). Technological development is therefore singled out as the most important factor in initiating and expanding distance, online and blended learning, where the educational process is mainly facilitated by educational technologies. Verene (2013:297) explains that technology does not look back, but promises a better future, because everything that we want to do can be done better with technology. This he describes as the 'technological bluff' that creates the impression that there is almost nothing that is not possible with technology. It is just a matter of time.

This optimistic view of technology creates the ongoing need for the use thereof and is underpinned with the notion that technology is good and necessary. Chau (2010) based her thoughts and critique on the optimistic view of technology on the classic work of Postman (1992). Postman described the utopian view of technology with the term Technopoly:

Those who feel most comfortable in Technopoly are those convinced that technical progress is humanity's supreme achievement and the instrument by which our most profound dilemmas may be solved. They also believe that information is an unmixed blessing, which through its continued and uncontrolled production and dissemination offers increased freedom, creativity, and peace of mind. (p. 71)

There are certain assumptions and even beliefs with regard to technology that deem to be important for this discussion to sketch the accelerated development thereof, as well as the increasing need to utilise it specifically in education. These assumptions concerning students are that they are intrinsically motivated enough to study on their own and in their own time and that face to face learning could be replicated in online education. In the words of Verene (2013:297): 'The guiding principle is that anything that can be accomplished in the traditional classroom can be done electronically'. However, he argues that information could be stored via technology, but construction of knowledge and especially a lecture, cannot be replicated online. He describes 
a lecture as a live performance of a person thinking and the students thinking with the lecturer by taking notes and posing questions (Verene 2013:300). Online education lacks the rhetorical presentation of a face-to-face lecture. Instead, online education reduces students to clients and consumers of information that is available worldwide and decontextualises contents to information that assumes one size fits all (Verene 2013:303). He makes a distinction between 'the technical operation' and 'technical phenomena'. The 'technical operation' refers to technology as a tool that could be used, while the 'technical phenomena' refers to how technology affects our way of thinking and being. The technical phenomena imply that it encompasses our dreams and vision of the future. It means that our expectation and hopes are fixed on what technology can achieve (Verene 2013:303). In general, it seems that the improvements associated with online learning made possible by technology are overrated without little credence to what is lost in the process (Sinclaire 1998:297-298).

\section{The commodification of knowledge and education}

The complex phenomenon of the commodification of knowledge could be described in different ways. For that very reason, I do not claim to give a final and single understanding thereof. I found Radder's (2010:4) perspective helpful, explaining that commodification could be identified with commercialisation explaining it as follows: '... the pursuit of profit by academic institutions through selling the expertise of the researchers and their results of their enquiries'. Furthermore, academic commodification is not standing loose from other social developments but is deeply embedded within and part of that. Academic commodification implies further that academic activities and its results are mainly interpreted and assessed with economic criteria. Decreased governmental funding according to Radder (2010:6), gave way to patents as a form of commodification of research, which became an accepted practice in departments like biomedical science. In social science, for instance, the commodification of research will take the form of contract research. These practices became accepted as common practice at universities and will therefore receive lesser and lesser questioning and scrutiny. Education will therefore be increasingly geared towards the market rather than the citizen (Radder 2010:40).

Amory (2012:42) contents that '... many education practices foster the neo-liberal dream of power, commercialization and profit making'. He explains it implies that education systems make use of market principles and practices. Furthermore, these neo-liberal agenda are instructive of nature and that is one of the main critiques that Amory (2012) has against the current education system where technology is central. While technological development is rapidly taking place, teaching, learning and assessment practices have not necessarily changed. The article will refer to two forms of how technology is utilised in education at universities, namely online education and a blended learning model.
Online education that is mainly facilitated by technology becomes a long-term strategy for instruction in higher education in order to survive in an uncertain future and competitive market, resulting in training centres instead of places of learning (Chau 2010:183). Although online education is often viewed as the answer in providing access and flexibility in education, it is not always valued in the same way than residential training (Chau 2010:18). Chau (2010:19) demonstrates this tendency by referring to a survey by Adams and DeFleur (2006), who found that employers prefer applicants who received traditional training instead of an online degree. An even more surprising finding was that institutions are less likely to accept candidates with an online degree into their degree programmes.

Blended learning is the educational model utilised by more and more residential universities. Blended learning can be understood as a mixture between face-to-face classroom activities and online technology learning activities (Zhonggen 2015:1). This combination of online and classroom activities, however, is not as simple as it may seem for both students and educators. This combination assumes the successful or effective blending of learning and teaching to enhance face-toface education and reaching learning outcomes. Many factors play a role in the effectiveness of blended learning as educational model, namely the learning context, characteristic of student population, the mission of the institution, responsiveness of faculties, availability of resources, etc. One of the biggest challenges with regard to effective implementation of blended learning as educational model is the unwillingness to change at an institutional level (Zhonggen 2015:11). Despite its popularity, blended learning still presents different challenges that cannot be ignored, like reluctance on the part of institutions to undertake major modifications. Furthermore, blended learning could imply loss of finance and time because there seems to be a weak correlation between this educational model and student's success or persistence. Students' passive participation is another challenge (Zhonggen 2015:13). Amory (2012) is much more critical of blended learning and argues that it is a term used to redeem money unwisely spent on a compromise position, as well as an attempt to save face. 'The approach is to replicate past practices into the future while professing to embrace change' (Amory 2012:47). In this process, technology is not a tool that supports knowledge construction, but rather the object of the learning.

\section{Technology as a driving force behind the commodification of education}

Words like knowledge economy and information economy are part of our everyday vocabulary and underline the connection between economy and education today. One way of explaining this connection is by understanding the driving force behind technological developments and the use thereof with the ideology of capitalism. A report from the World Bank (2003:1) defines a knowledge-based economy as an economy that '... relies primarily on the use 
of ideas rather than physical abilities and on the application of technology'. The rapid changing needs and demands for skilled workers are an integral part of the knowledge-based economy, and therefore, this report argues for lifelong learning. This means that ongoing training and learning is needed to be an active participant in a competitive, global knowledge-based economy. Because the application of technology is an integral part of education in such economy, technology adoption is strongly linked to the education of the labour force. Society therefore relies on technology as well as the creation and distribution of knowledge as part of knowledge economy.

The challenges that are brought along by an knowledgebased economy in especially developing countries like South Africa, are formulated as '... the dual challenge of addressing the longstanding issues of access, quality and equity while moving towards as lifelong learning system' (World Bank 2003:8). Access to technology and technological literacy are a part of the challenges faced in a developing country like South Africa. These challenges are often described as the digital divide referring to those that have access to technology and technological skills and those that do not (Cloete 2015:147). Chau (2010:186) also warns that the push towards, for example, online education where the use of technology forms the basis masks the reality that not everyone has access to technology or the skills to use it and would therefore not benefit from it.

Lelliot, et al. (2001:2) also warn that this social embeddedness of technology leads to an unavoidable dilemma in Africa. Without advanced technology, Africa will be excluded from global development, but access to technology 'will bring new forms of exclusion and new risks'. Moreover, it has implications for distributive justice because where money is spend on infrastructure to secure technology use, it means that that money cannot be used to provide people's basic needs like shelter, food, health care and education. Although it is often assumed that technology will better the world and peoples' lives, there is no sufficient proof thereof in South Africa and the rest of Africa. Therefore, the push for the advancement of technology in these contexts could lead to even more poverty and exclusion, although it is difficult to believe or accept, especially when the optimistic view of technology is the prevailing one. In the words of Lelliot, et al. (2001:4), 'Where people lack the capacities to exercise an opportunity, the opportunity is empty'.

The learning society promise, primarily created through technology, is viewed as a myth by some, because 'the very notion of learning is under-theocratized ...' (Lelliot, et al 2001:1). The learning societies, especially in Africa, are faced with unavoidable dilemmas concerning Information Communication Technology (ICT). Because of the lack of access and stable structure needed to use technology, the use thereof could lead to new forms of exclusion and risks. Furthermore, the use of ICT in education assumes that the basic education is of a good standard, which is currently not the case, for example, in many African countries (Lelliot et al. 2001:2). Wilkinson, Wilkinson and Nel (2001) corroborates by stating:

... despite the funding being pumped into the provision of new online education programmes by South African institutions of higher education, this type of education is not likely to meet the demands of this country. (p. 135)

A large part of the population does not have access, while those who might have access do not have quality network and infrastructure. Not only physical access is needed but also epistemological access, requiring both students and lecturers to be computer literate as well as conventionally literate and numerate.

Martin (2007) asks the question whether online education is a well-founded pedagogy or serving states interest. In his attempt to respond to this question, he also makes a noteworthy contribution to the growing critical discourse on ICT in higher education. He argues, contrary to the more popular view with regard to technology in education, it has the potential to increase costs, limiting access and reducing education to a commodity that is mainly driven by profitmaking capitalist transnational corporations (Martin 2007:479). Because there is no substantive proof that the use of ICT in education contributes to good pedagogy, he concludes that the enthusiasm to utilise it rather comes from those who will benefit from selling the technology to universities and other institutions. Furthermore, despite the fact that more money is spent on technology at universities, the budgets are shrinking for the appointment of new staff. This could lead to a situation where more money is spent on infrastructure and software for the different ICT programmes at universities than on the development of staff and students. Universities therefore have to find new ways to fund teaching and research, and one way of doing that is by increasing student fees:

The result is that students have to get loans to pay higher fees, have to purchase hardware and software that enables them access to educational ICT, and simply have to take responsibility for their own learning ... (Martin 2007:481)

Keengwe and Georguna (2013:52) argue that the integration of technology into education could meet the needs of the Millennials as the generation currently attending universities. They describe the characteristics of this generation as wanting to construct their own learning content and process, wanting to work in teams and have sophisticated knowledge and skills of information technologies. At the same time, they are cautious about the instrumentalist understanding and use of technology, whereby technology is understood as an end in itself. Technology should not drive instruction, but should rather be integrated into the curriculum and not the other way around. 'Technology is not a substitute for good instruction' (Keengwe \& Georguna 2013:57).

I would like to highlight how the use of technology has the potential to alter the role of the educator, student and ultimately that of the university. Utilising technology in 
education redefines what educators do and ultimately implies a change in pedagogical rationale (Söderström et al. 2012:2). $\mathrm{Nel}$ (2008:97) describes the changing role of the student as a customer and a client in a context where learning and knowledge are increasingly commodified. He further describes this process as reducing learning and knowledge to fit the market's needs and priorities. Closely linked and arguably the most important of these ambitious aims are achieving profits, placing the pursuit of knowledge of secondary importance. Nel (2008:98) also points out how the naming of positions at universities mirrors that of the business world, like programme managers and school directors.

Chau (2010:181) argues that the deterministic view of technology allows education and society to be appropriated by the corporate world. The function of institutions of higher education changed from being in the business of education into being in the education business, where critical thinking will not necessarily be of primary concern. Moreover, this change in the focus of education and the functioning of universities will lead to commercially orientated professionals instead of public-interest professionals:

Subsequently, education will no longer be about learning, but reaching economic goals that are set by the 'experts' with an increasing number of them acting more like corporate executives than educators. (Chau 2010:181-182)

The increased cooperation between universities and the business world also leads to a blurring of lines between the corporate world and institutions of higher education. Although education has never been beyond the reach of business, the role of education is much more than the production of knowledge, but prepares students to be critical aware citizens. Equally important is the role of education in shaping students' values and identities. In short, education should make a significant contribution to the being functions of students and not only their doing function.

Alongside these challenges identified in the forgoing discussion, there are also new possibilities that need to be explored and therefore the following section will identify the opportunities that technology offers specifically to theological education.

\section{Opportunities offered by the integration of technology into education with specific reference to theological education}

One of the certain gains of the advent of technology in education is that it stimulated much needed in-depth discussions and caused teachers to rethink their pedagogical models (Ascough 2004:28). The first section discussed the complex nature of technology as socially embedded medium, as well as the challenges it poses to the broader society - in general and education specifically. The focus on theological education is motivated firstly by my own involvement with theological training and secondly by the fact that people in
South Africa are deeply religious and therefore society and even government heavily depends on ordained ministers to lead churches to meaningful engagement in society (Naidoo 2015:166). This implies that theological training is key in order to serve not only churches but also the broader society.

Educational institutions cannot ignore the possibilities that educational technologies could offer and therefore time and money should be invested in training staff to utilise educational technology in a pedagogically sound manner. Olivier (2014:2-3) did research on the integration of technology into theological education at Unisa. She places the development of technology within the framework of a revolution and gives a concise description of revolution as a process that is accompanied with stress, uncertainty, discomfort and a need to adapt. A commitment to adjust and be flexible is therefore paramount in order to have transformed educational approaches. This commitment to adjust in a changing educational environment must include continuous training for staff and students to use technology and research on how to make use of technology in a manner that is pedagogically viable.

According to Olivier (2014:3), theology took up the challenge to utilise the printing press and should do the same with the new technology. The impact of theology is directly related to the medium used throughout the ages. Therefore, an urgent invitation to embrace technology specifically in theological education, is made. Although her arguments seem to mainly function within an instrumentalist understanding of technology, it is still noteworthy to bring especially theology to the centre of society and education today. Educational technologies could also enhance interdenominational, intercultural, international and interdisciplinary theological education and at the same time broaden the audience for theology (Olivier 2014:4). The interactive nature of educational technology could also enable reflective practices. Reflection is key in all learning processes. Reflection requires connection with previous learning and dialogue with different perspectives that could enable students to be change agents (Baporikar 2016:15). 'A change agent is someone whose presence and / or thought processes cause an alteration from the traditional or conventional way of handling and thinking about an issue' (Olivier 2013:2).

Both Delmater (2004:137) and Ascough (2002:19) point out that participation is better in online education. Classroombased education often provides a forum for extrovert learners to participate, while introverts find it difficult to participate, resulting in difficulty in allocating marks for participation. Online education, however, provides an environment where all and often marginalised voices could be heard, contributing to a higher participation of students as well as collaborative learning. The fluid nature of technology in online education, where time and spaces do not limit connection, creates an environment where students have to take greater responsibility for their own learning process and continuous participation is more the norm than the exception (Kerr 2005:1-1012). Research by Olivier (2013:5) confirms that 
online education could conceptualise and design in such a way that it increases students' participation. Students' feedback indicates that the course makes them aware of their social responsibilities as citizens, as well as to assist with the integration of what they believe into their everyday living. The interactive nature of technology could help students to develop essential skills, like being co-producers of knowledge and to monitor and organise themselves. Moreover, their active participation in the learning process could create a space where learning and teaching could be fun, something that is not often associated with learning (Olivier 2014:5).

Disembodiment that is part of online education seems to be one of the biggest challenges, especially in theological training (Cloete 2015:149; Delmater 2004:137). Delmater et al. (2007:74-75), however, give a more nuanced understanding of embodiment that counter the idea that physical presence is the only authentic way of embodiment. They substantiate their argument by stating firstly that online education could also create experience between students and educator and more importantly, between students that could expand outside the classroom time and space. Secondly, they argue that there are different kinds and more difficult forms of distance between students and teacher, like cultural distance, gender and class historical distance. These forms of distance are often overlooked and ignored in education, even in faceto-face classroom-based education. Ascough (2002:19) argues that online education changes the dynamics around class, race and gender issues and could minimise discrimination and prejudice.

Lastly, Delmater et al. (2004:137) proposes a theological anthropology of an integration of spirit and soul that does not allow a dual understanding of body and soul. Therefore, it could be argued that the questions that educational technologies place on the table also have the potential to challenge our theological assumptions with regard to human beings and their way of being in the world. Research by Kim, Song and Luo (2016:672) also argues for a broader understanding of social presence, especially with regard to online education. Social presence can be defined in various ways, but in short, it entails the awareness of the other person during interaction. In a mediated environment where the engagement is facilitated and mediated by technology, social presence signifies the presence of the other person(s), although the person is not physically present in the same space. Kim et al. (2016:674) concluded that social presence is multidimensional in nature and encompasses both presence as psychological involvement as well as co-presence. Because of the continuous connectivity that is possible, technology could also bridge the dichotomy that often exists between theory and practice. This dichotomy stems often from the separation between the academic training and the church context. Religious leaders from churches could be included via the Internet in discussion with students and contribute to the diversity of perspectives and in minimising the gap between theory and practice (Litchfield 1999:104).
Bauman et al. (2014:308) postulated that cyberspace gives opportunities for deep engagement, self-representation and expression that could constitute spirituality in a global context. While the aim of education is often that students should develop critical thinking, the goals of students are often to develop their own beliefs and values. Theological education is well positioned to use the technological capabilities of theological students to cultivate meaningful engagement with students from other religions than their own. The ability to converse in a multi-religious context is paramount for religious leaders today. The plethora of opinions and information that students are confronted with online could challenge them to develop the skill of discernment about what to read and in a creative way form their own opinion. To make selections from information is not only possible but also is the norm and therefore students are challenged to select wisely from an increasingly complex inverse of data that is available (Bauman et al. 2014:11; Kerr 2005:1012).

\section{Conclusion}

Technology is an integral part of living in the 20th century, referred to as the fourth revolution accompanied with challenges and opportunities. The overall aim of the article is to illustrate the complexity of technology as embedded in other social developments. Technology also has a structural character and therefore has the ability to include and exclude. Technology is therefore understood as more than gadgets that could be utilised, but also implies an attitude towards life. The article attempted to illustrate that the impact of technology in education is not linear, but as much as it presents various opportunities, it also poses several challenges. These challenges and opportunities are directly linked to the nature of technology and socially embedded medium. The article outlined the implications for the integration of technology into education for the South African context in general and theological education specifically.

\section{Acknowledgements Competing interests}

The author declares that she has no financial or personal relationships which may have inappropriately influenced her in writing this article.

\section{References}

Adams, J. \& DeFleur, M.H., 2006, 'The acceptability of online degrees earned as a credential for employment', Communication Education 55(1), 32-45. https://doi. org/10.1080/03634520500343376

Allenby, B.R. \& Sarew, D., 2011, The techno-human condition, The MIT Press, Cambridge.

Amory, A., 2012, 'Instructivist ideology: Education technology embracing the past?', Interactive Learning Environments 20(1), 41-55. https://doi.org/10.1080/ 10494821003714707

Ascough, R.S., 2002, 'Designing online distance education: Putting Pedagogy before technology', Teaching Theology and Religion 5(1), 17-29. https://doi.org/ 10.1111/1467-9647.00114

Baporikar, N., 2016, 'Technology integration and innovation during reflective teaching', International Journal of Information and Communication Technology Education 12(2), 14-22. 
Bauman, W., Marchal, J.A., Mclain, K., O'Conneil, M. \& Patterson, S.M., 2014, 'Teaching the millennial generation in the religious and theological studies classroom' the millennial generation in the religious and theological studies classroom',
Teaching Theology and Religion 17(4), 301-322. https://doi.org/10.1111/teth.12237

Chau, P., 2010, 'Online higher education commodity', Journal for Computer and Higher Education 22, 177-191. https://doi.org/10.1007/s12528-010-9039-y

Cloete, A., 2015, 'Educational technologies: Exploring the ambiguous effect on the training of ministers', in M. Naidoo (ed.), Contesting issues in training ministers in South Africa, pp. 141-154, Sun Press, Stellenbosch.

Delmater, S., 2004, 'A typology of the use of technology in theological education', Teaching Theology and Religion 7(3), 134-140.

Delmater, S., Alanis, J., Haith, R., Hoffman, M.V., Jones, A.W. \& Strawn, B.A., 2007, 'Technology, pedagogy, and transformation in theological education: Five case studies', 10(2), 64-79. https://doi.org/10.1111/j.1467-9647.2004.00203.x

Drees, W.B., 2002, 'Human meaning in a technological culture: Religion in an age of technology', Zygon 37(3), 597-604. https://doi.org/10.1111/1467-9744.00439

Hess, M.E., 2002, 'Pedagogy and theology in cyberspace: “All that we can't leave behind..."', Teaching Theology and Religion 5(1), 30-38.

Keengwe, J. \& Gergina, D., 2013, 'Supporting digital natives to learn effectively with technology tools', International Journal of Information and Communication Technology Education 9(1), 51-59. https://doi.org/10.4018/jicte.2013010105

Kerr, S.T., 2005, 'Why we all want to work: Towards a culturally based model for educational change', British Journal of Educational Technology 36(6), 1005-1016. https://doi.org/10.1111/j.1467-8535.2005.00570.x

Kim, J., Song, H. \& Luo, W., 2016, 'Broadening the understanding of social presence: Implications and contributions to the mediated communication and online education', Computers in Human Behavior65,672-679. https://doi.org/10.1016/j.chb.2016.07.009

Lelliott, A., Pendlebury, S. \& Enslin, P., 2001, On-line education in Africa: promises and pitfalls, South African Journal of Information Management 3(1), 1-10.

Litchfield, R., 1999, 'Webs of connection using technology in theological education', Teaching Theology and Religion 2(2), 103-108. https://doi.org/10.1111/14679647.00049

Martin, R., 2007, 'Online education and training: Well-founded pedagogy or state corporate interest?', South African Journal of Higher Education 21(3), 473-484.
Naidoo, M., 2015, 'Ministerial formation and practical theology in South Africa' International Journal of Practical Theology 19(1), 164-188. https://doi.org/ 10.1515/ijpt-2015-0004

Nel. J., 2008, 'Trends in higher education: Selling out?', Journal for New Generations Sciences 13(1), 96-104.

Olivier, E., 2013, 'Teaching open distance learning undergraduates in theology to become effective change agents', Verbum et Ecclesia 34(1), 1-7. https://doi. org/10.4102/ve.v34i1.845

Olivier, E., 2014, 'Theological education with the help of technology', HTS. Theological Studies 70(1), 1-7. https://doi.org/10.4102/hts.v70i1.2643

Postman, N., 1992, 'The broken defenses', in N. Postman (ed.), Technopoly: The surrender of the culture to technology, pp. 70-91, Vintage Books, New York.

Radder, H., 2010, The commodification of academic research: Science and the modern university, University of Pittsburgh Press, Pittsburgh, PA.

Saravanamuthu, K., 2002, 'Information technology and ideology', Journal of Information Technology 17, 79-87. https://doi.org/10.1080/02683960210 145977

Sinclair, J., 1998, 'Does the virtual classroom really exist ... or is it still... out there', The Electronic Library 16(5), 297-299. https://doi.org/10.1108/eb045653

Söderström, T., From, J., Lövqvist, J. \& Törnquist, A., 2012, 'The transformation from distance to online education: Perspectives from the educational management horizon', The European Journal of Open, Distance and E-Learning (1), 1-9.

Verene, D.P., 2013, 'Does online education rest on a mistake?', Academic Quest 26, 296-307. https://doi.org/10.1007/s12129-013-9367-2

Wilkinson, A., Wilkinson, L. \& Nel, G., 2001, 'Balancing quality and access in online education', Acta Academia 33(2), 127-145.

World Bank, 2003, Lifelong learning in the global knowledge economy: Challenges for developing countries, World Bank, Washington, DC

Zhonggen, Y., 2015, 'Blended learning over decades', International Journal of Information and Communication Technology Education 11(3), 1-19. https://doi org/10.4018/IJICTE.2015070101 